\title{
Evaluating salinity damage to crops through satellite data analysis: application to typhoon affected areas of southern Japan
}

\author{
Kensuke Goto • Takehiro Goto • Jephtha C. Nmor • \\ Kazuo Minematsu $\cdot$ Keinosuke Gotoh
}

Received: 1 October 2013/Accepted: 1 October 2014/Published online: 26 October 2014

(C) The Author(s) 2014. This article is published with open access at Springerlink.com

\begin{abstract}
In recent times, tsunamis and typhoons have threatened Japan's coastal lands with increased flooding and salinity. Using satellite data, we monitored the effect of increased salinity on vegetation health in the coastal area of southern Japan, which was affected by flooding following Typhoon 9918 in 1999. An index of plant activity called the Normalized Difference Vegetation Index (NDVI) was evaluated before and after the typhoon, and the change in NDVI was computed as a comparison measure. The results were then correlated with electric conductivity, which is a measure of soil salinity. A strong negative correlation was found between NDVI ratio and salt concentration $(r=$ $-0.7731, n=50, p<0.0001)$, indicating that the reduced NDVI values were attributable to increased salinity from the flooding. These results not only provide useful insight into a rapid method of assessing large-scale flood impacts using satellite data, but also validate the monitoring of NDVI as an indicator of salinity damage to vegetation. To summarise, by understanding the changes in vegetation health following natural disasters such as flooding (as revealed by NDVI), we can potentially develop improved management strategies.
\end{abstract}

Keywords Salt damage $\cdot$ Flood tide $\cdot$ Satellite data $\cdot$ NDVI $\cdot$ EC

Keinosuke Gotoh-Professor Emeritus

K. Goto $(\bowtie)$

Osaka Kyoiku University, 1-2-10 Midorigaoka, Ikeda, Osaka 563-0026, Japan

e-mail: goto@cc.osaka-kyoiku.ac.jp

T. Goto

Saga University, 1 Honjo-machi, Saga 840-8502, Japan

J. C. Nmor

Delta State University, Abraka, Nigeria

K. Minematsu

Juntendo University, 2-1-1 Hongo, Bunkyo-ku, Tokyo 113-8421, Japan

K. Gotoh

Nagasaki University, 1-14 Bunkyo-machi, Nagasaki 852-8521, Japan 


\section{Introduction}

Globally, agriculture has performed remarkably well over the past couple of decades, adapting to rapid population growth and delivering food at progressively lower prices. However, in the coastal wetlands of Japan, this success is threatened by natural disasters such as flooding and tsunamis. These natural phenomena increase the soil salinity of agricultural land and endanger the soil micro-flora and micro-fauna (Fritz et al. 2007, 2009, 2011; Moore et al. 2011; Tchiadje 2007).

Japan was affected by flooding caused by Typhoon 9918 in 1999, and the tsunami generated by a huge earthquake on 11 March 2011. Following these events, saltwater and sediment were deposited across the cities surrounding the Pacific Ocean. The salts and deposits may alter the salinity of soil and groundwater in affected coastal areas and cause salt injuries in crops. Large floods and tsunamis occasionally cause extensive salt damage by the infiltration of seawater, incurring catastrophic ecological and economic cost.

Salinisation of soil and groundwater by tsunamis and flooding is detrimental to agricultural production (Kume et al. 2009). Adequate water and nutrients are essential for successful crop production. As has been well documented, excessively saline water and soil imposes environmental stress on plants, inhibiting their growth (Leone et al. 2000; Turhan 2005). Plants under salinity stress exhibit symptoms at physiological, and even molecular, levels (Turhan 2005).

Salt damage to crops is caused not only by osmotic forces, but also by toxic levels of sodium and chloride. As the sodium content of the soil increases, sodium ions are more likely to be absorbed by the humus complex. Excessive sodium absorption also hardens and compacts the soil, so that rain and irrigation water remain at the soil surface without penetrating the root zone. Compounding the problem, excess sodium raises the $\mathrm{pH}$ of the soil. At elevated $\mathrm{pH}$, certain soil nutrients are sequestered and thereby become unavailable to the plant. In summary, salt adversely affects production in tsunami-stricken areas by increasing the alkalinity of soils, impeding the intake of potash nutrients by crops through the cation exchange capacity (Tchiadje 2007).

The consequences of salt accumulation in agricultural soils are reduced plant growth rates, diminished yields and (in severe cases) total crop failure, all of which threaten the sustainability of agricultural production (Aldakheel 2011; Ashraf and Harris 2004; Zeng and Shannon 2000). Mitigating and controlling the salinity problem requires a rapid, reliable and cost-effective method of evaluating soil salinity in the root zone. Such a method can be realised by integrating remote sensing (RS) data and geographic information systems (GIS) technologies.

Because remote sensing equipment observes a wide area at any one time and regularly observes the same location, remotely sensed data have recently been used to assess the impact of floods, tsunamis and other natural disasters (Barnes et al. 2007; Fritz et al. 2008, 2011; Gotoh et al. 1999; Kume et al. 2009; Liu et al. 2013; McAdoo et al. 2007; Middleton 2009; Nuttall and Armstrong 2010; Overton et al. 2006; Ramachandran et al. 2005; Rodgers et al. 2009; Suppasri et al. 2012; Velmurugan et al. 2006). Furthermore, the effects of salinity on vegetation (Wang and Xu 2008) and the impact of sea water and soil salinity (Dan and Richard 2002; Datta and Jong 2002; Fritz et al. 2011; Gotoh et al. 1999, 2012; McAdoo et al. 2007; Middleton 2009; Overton et al. 2006) have been evaluated from satellite data. In particular, satellite data provide a vegetative activity measure called the Normalized Difference Vegetation Index (NDVI), by which the impact of salinity on agricultural crops and other vegetation can be quantified. 
Since salinity and exposure to force winds may alter (Gong et al. 2007; Wilson et al. 2006), it is hypothesised that the flood generated by Typhoon 9918 brought an influx of seawater to northern Kumamoto, Japan, which has compromised the health of vegetation in the coastal wetlands of that area. However, no peer-reviewed research has been published on the effects of post-Typhoon 9918 flooding on the exposed vegetation.

Here, we investigate the changes in vegetation health in the cultivated areas of Kumamoto Prefecture from the measured NDVI values. We then identify the link between NDVI and soil salinity, aiming to estimate the vegetation damage caused by increased salinity after the typhoon 9918-generated flooding. Finally, we construct an NDVI distribution map across the studied area.

\subsection{Typhoon 9918 profile}

Figure 1 shows the path of Typhoon 9918 in the study area (Kumamoto Prefecture, Japan) on 24 September 1999. Quoting the (Japan Weather Association 2000), the typhoon 'began at 0900 hours on 17 September 1999, on Okinawa's South Sea and reached northern Kumamoto Prefecture with medium strength at 0600 hours on 24 September 1999. It became an extratropical cyclone off Abashiri at 1200 hours on 25 September 1999'. The maximum recorded wind speed was $66.2 \mathrm{~m} / \mathrm{s}$. To date, no higher wind speed has been reported by Kumamoto's Ushibuka Meteorological Observatory.

Flood tides are unusually high tides caused by dramatic drop in air pressure in the presence of strong winds such as typhoons. As a typhoon with a low-pressure core approaches, it exerts a suction effect on the sea surface, raising the tide level. In addition, seawater can accumulate in winds blowing onshore from the sea. Bays open to the south are particularly prone to tide winds when a typhoon moves north along the west bank and southerly winds persist.

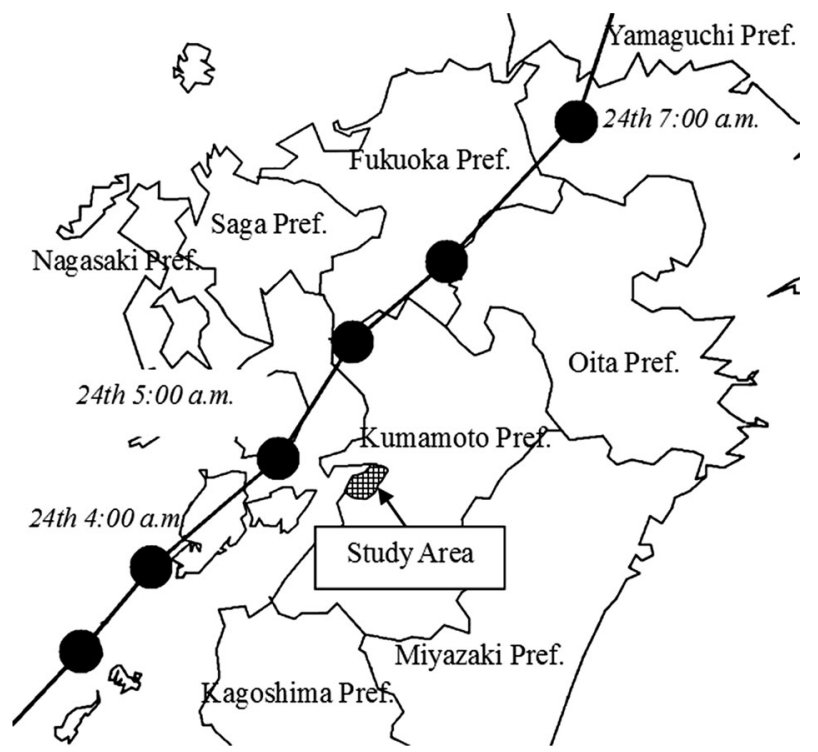

Fig. 1 Course of Typhoon 9918 in the Kumamoto prefecture (the study area) on 24 September 1999. Original map provided by the Fukuoka District Meteorological Observatory 
Typhoon 9918 generated the highest tide level of the year during the early hours of 24 September 1999, when it arrived in north Kumamoto Prefecture and aggravated the spring tides. Furthermore, the disaster-stricken Shiranui region was rendered vulnerable by its tidal flat topographic nature comprising a long narrow bay surrounding the Yatsushiro Sea (Takikawa 2000). As the typhoon moved north along the west side of Kumamoto Prefecture (see Fig. 1), it damaged Shiranui and other regions with conditions, especially conductive to flood tides.

\subsection{Damage profile}

Besides destroying human lives and properties, Typhoon 9918 caused severe crop damage due to influx of seawater by flood tides. The estimated cost of agricultural damage in former Ryuhoku Town, the most damaged region of the affected area, was US $\$ 48.96$ million. Most of the reclaimed land in Shiranui was flooded at the nick of harvest; thus, the entire agricultural produce was lost.

Seawater dragged by the typhoon inundated 2488 ha of agricultural land across the Kumamoto, Yamaguchi and Fukuoka prefectures. Increased salinity accounted for almost all of the agricultural damage in the affected area. Salt accumulation was observed in the soils of former Ryuhoku, Matsubase, Uki, Shiranui, Ogawa and Kagami Towns, affecting successive seasonal farming activities until the soil was desalinated by the Ministry of Agriculture, Forestry and Fisheries. The vegetation in these areas was mostly Soft Rush. This vegetation was negatively affected after typhoon 9918. Kumamoto Prefecture estimated the costs of restoring the area damaged by Typhoon 9918 as $\$ 11.95$ million. The soil desalinization has been started after the soil salinity survey in 1999. After the removal of saline sludge, drainage system has been improved. Then the approximately two times of ponding and drainage have been performed in each rice field. These processes took for 3-5 months (Kumamoto Prefecture 2001).

The state of the agricultural land in the aftermath of the disaster is illustrated in Fig. 2ad. Panels (a) and (b) of Fig. 2, respectively, show the flooded region immediately after the damage and the state of Soft Rush grass (Juncus effusus) 1 week later. As demonstrated in these images, salt damage and healthy Soft Rush were not easily distinguishable immediately after the event; however, salt damage became evident 1 week later (Fig. 2b) and the Soft Rush became red before withering. This implies that an internal change occurred in the Soft Rush during the 1 week period. Figure $2 \mathrm{c}$, d show the agricultural land covered by a thick layer of saline sludge carried from the sea by the flood tides.

Figure 3 shows the damage surveyed on site. A map of the flooding is presented in Fig. 3a. The flood tides has overflowed from revetment $(+5.3 \mathrm{~m})$ lower than sea wall $(+7.0 \mathrm{~m})$, after then flooded into residential area $(+2.7$ to $+3.4 \mathrm{~m})$. The estimated highest high water level was $+6.7 \mathrm{~m}$. According to interview surveys, major flood damage immediately killed the Soft Rush and glutinous rice in areas around flooded and burst banks. Figure $3 \mathrm{~b}$ maps the salt damage distribution constructed from surveys. Since the damage is visually difficult to classify, a detailed assessment is not possible from these data alone. Hence, the state of the damage was determined from proxy vegetation indices extracted from satellite data.

\section{Materials and methods}

When coastal lands are flooded by high tide disasters, the altered soil salinity affects the land vegetation in tandem. Considering that salt enters the vegetation and reduces its 
a
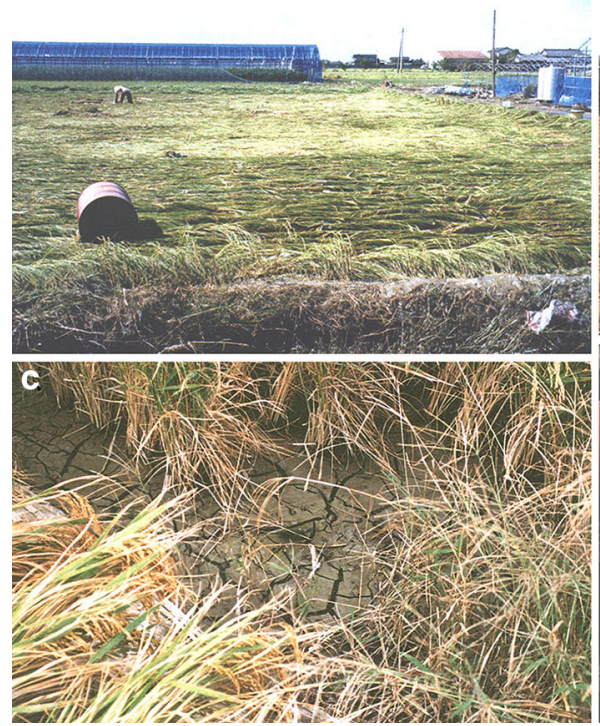

b

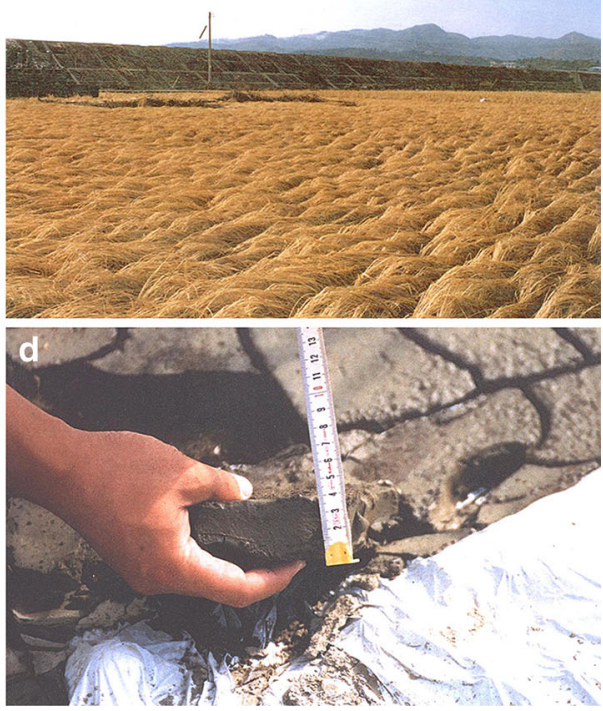

Fig. 2 Agricultural produce damaged by Typhoon 9918. a Soft Rush immediately after damage (Source: Former Ogawa Town, Town Hall). b Soft Rush 1 week after initial damage (Source: Former Shiranui Town, Town Hall). c Agricultural land-damaging saline sludge, 1 (Source: Former Shiranui Town, Town Hall). d Agricultural land-damaging saline sludge, 2 (Source: Former Shiranui Town, Town Hall)

activity, a correlation between NDVI ratio and soil salinity in salt-damaged areas would validate the NDVI ratio monitoring method as a means of identifying salt damage.

To ascertain the damage characteristics, this study initially referred to various compiled materials (such as typhoon profiles) and on-site survey results (such as maps of flooded areas and salt damage). The flooding survey was conducted by field survey finding the flood marks and hearing survey. The effectiveness of satellite monitoring methods was then determined by computing the vegetation indices from soil salinity surveys of reclaimed land in Shiranui and Ryuhoku Towns, Kumamoto Prefecture, and deciding whether these indices correlated with NDVI maps generated from satellite data of reclaimed land in Shiranui before and after the damage. The salinity survey was conducted with measure $\mathrm{EC}, \mathrm{Cl}$ and so forth of sample soil. This salinity survey has completed in not only one survey, but also throughout the all surveys. If a correlation exists, we conclude that vegetation index-based monitoring is an effective damage indicator, and we proceed to generate NDVI maps of the entire affected region. These results will confirm salt damage and determine whether disaster-stricken agricultural and forest land can be properly monitored by satellite data.

The region of interest, comprising areas surrounding the Yatsushiro Sea that experienced strong winds from the typhoon passing along the west side, is shown in Fig. 4. The images used in the study were Thematic Mapper (TM) images derived from the Landsat 5 satellite (ground resolution: $30 \mathrm{~m}$ ) collected on 4 October 1998 (before the typhoon), 7 October 1999 (immediately after the typhoon) and 23 October 1999 (2 weeks after the typhoon). The latter images were used to assess the progression of salt damage. Ideally, pre-typhoon data should have been collected immediately prior to the damage on 7 October 1999, because the composition of Soft Rush and glutinous rice crops in the affected area 

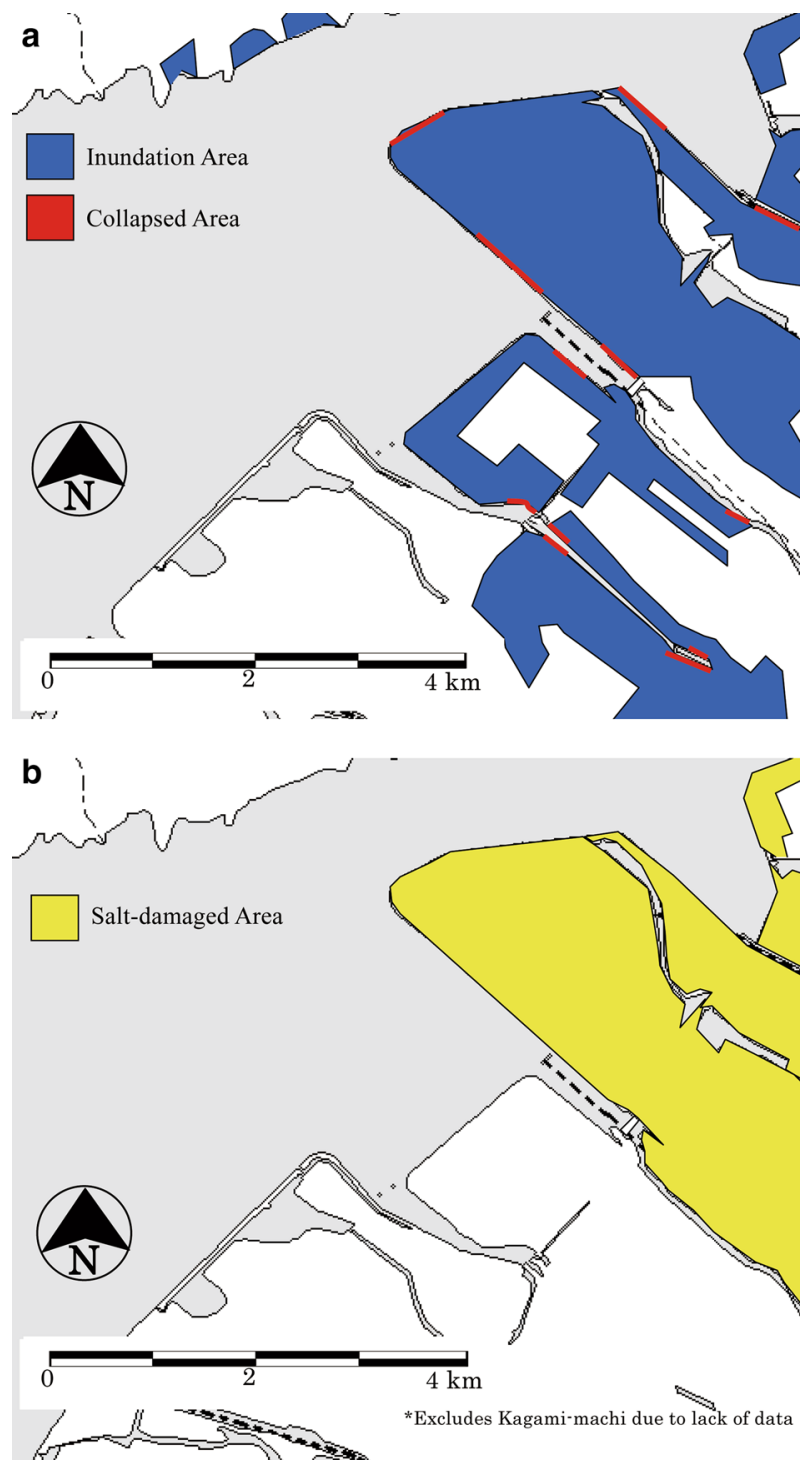

Fig. 3 Damage distribution maps compiled from on-site data. a Map of flooded regions (taken from contemporary Town Hall data). b Map of surveyed salt damage distribution (constructed by reference to contemporary town hall data)

varies over time. However, well-timed data (and hence a quantitative analysis) were precluded by the cycle of the Landsat satellite (17 days). Given that the agricultural produce was approximately the same on 4 October 1998 and immediately after the typhoon on 7 October 7 1999, we assumed that the data collected on the two dates would be similar. Indeed, contemporary Town Hall members and farmers confirmed that the growth situation and crop yields in 1998 were typical of those in the studied area. In addition, the growth progress and presumed crop yields in both 1998 and 1999 were confirmed as almost 


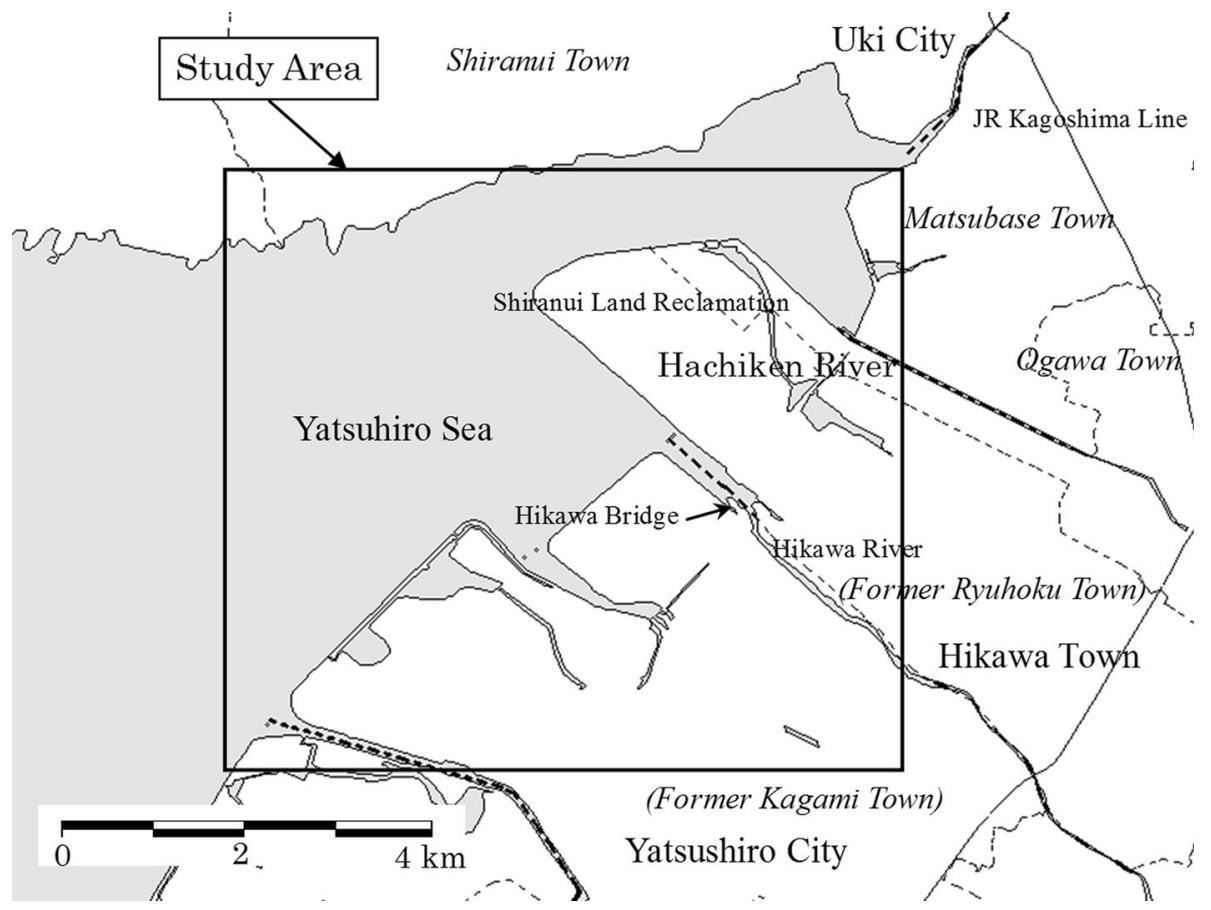

Fig. 4 Analysed study area

identical prior to the Typhoon 9918. Consequently, the 1998 data could be reliably considered as 'healthy' data when quantifying the effect of salt damage on vegetative activity.

The impact of salt damage was estimated from the pre- and post-typhoon vegetation indices. The NDVI were calculated from the Landsat TM data as follows:

$$
\mathrm{NDVI}=(\mathrm{TM} 4-\mathrm{TM} 3) /(\mathrm{TM} 4+\mathrm{TM} 3)
$$

where TM3 and TM4 are the reflected luminances of bands 3 and 4, respectively.

Next, the pre- and post-typhoon NDVIs were compared and their differences were determined by analysing the changes in vegetation activity resulting from the salt damage. The change in vegetation activity after the typhoon is quantified by the NDVI ratio:

$$
\text { NDVI ratio }=(\text { post }- \text { damage NDVI }) /(\text { healthy NDVI })
$$

In terms of the healthy (4 October 1998) and damaged (7 October 1999) vegetation, the NDVI ratio becomes

$$
\text { NDVI ratio }=(\text { NDVI on } 7 \text { October 1999 }) /(\text { NDVI on } 4 \text { October 1998 })
$$

The effect of salt damage was determined by comparing the 7 October data with data collected 23 October 1999, 1 month after the flooding. The NDVI ratio was then calculated as shown below.

$$
\text { NDVI ratio }=(\text { NDVI on } 23 \text { October 1999) } /(\text { NDVI on } 4 \text { October 1998 })
$$

If the post-damage NDVI is lower than the healthy NDVI, the plant activity has been reduced by the increased salinity. Conversely, a higher NDVI signifies enhanced plant activity. 
Converting the results of this analysis into an NDVI ratio map, we can assess the level of salt damage in the affected area. If the NDVI is reduced in a locality, that locality has been sufficiently affected by salt damage to alter the vegetation activity.

All individual satellite data were subjected to georeferencing and atmospheric correction. In all analyses, corrections were performed using PG-STEAMER version 4.2 (Pixoneer Geomatics Inc., Taejun, Korea) and ArcGIS version 9.2 (ESRI Inc., Redlands, California, USA).

Soil salinity is surveyed by measuring the electrical conductivity (EC) of each piece of land. In soil and agricultural sciences, the conductivity of the solvent saturating the soil indicates the saline content of the soil (Larcher 2003). Specifically, EC measures the ease with which electric current flows through a soil suspension in pure water (Chighladze et al. 2009; Kurtulus et al. 2009; Nuttall and Armstrong 2010). EC is proportional to the amount of dissolved salts; an EC of 2.0 or greater is considered unsuitable for agriculture. In this study, five on-site soil salinity surveys were conducted by the Kumamoto Prefectural Office after the flooding by the typhoon 9918, especially in the tip of Shiranui land reclamation. The pre-damage NDVI ratio map was compared with the post-damage EC data from 25 October 1999, close to the observation date of 23 October 1999.

A relationship between the NDVI ratio map calculated from satellite data and the EC measure of soil salinity would confirm the applicability of NDVI as a proxy of salt content. To determine whether such a relationship exists, the EC distribution map was superimposed on our constructed NDVI ratio map at 50 points arbitrarily selected by random sampling. The correlation between the EC and NDVI ratio was then determined.

\section{Results}

\subsection{Comparison of the soil salinity survey and NDVI ratio maps}

Figure 5 shows the soil salinity survey colour map (Fig. 5a) superimposed on the NDVI ratio map (23 October 1999; Fig. 5b is a superposition of the two maps on 4 October 1998). For each of the arbitrarily chosen 50 points, the NDVI ratio and EC were compared and presented as a scatter plot of NDVI versus EC (see Fig. 6). The correlation has been calculated between EC collected by salinity survey and NDVI ratio of approximately 1 month after the typhoon. The NDVI ratio and EC are significantly negatively correlated, with a hazard rate below $1 \%$ (Spearman's rank coefficient $r=-0.7731, n=50$, $p<0.0001)$. Thus, we have validated the use of damage classification maps constructed from the NDVI ratio to identify salt-damaged regions.

\subsection{NDVI ratio mapping of the entire studied area}

In the previous subsection, the strong negative correlation between salinity and NDVI ratio confirmed the effectiveness of monitoring by vegetation indices. Therefore, we generated NDVI ratio maps of the entire studied area from the satellite data. Figure $7 \mathrm{a}-\mathrm{c}$ shows the NDVI maps of the area. The same colour scale is used on all NDVI maps, but the threshold of each panel is individually chosen to maximise readability.

Figure 7a is the pre-typhoon NDVI map from 4 October 1998, showing the pre-damage state. Agriculture in the affected area was healthy and data were collected during the harvest period; consequently, the NDVI was high across the entire area. By contrast, Fig. $7 b$ shows the NDVI map for 7 October 1999, 13 days after the salt damage. While the 

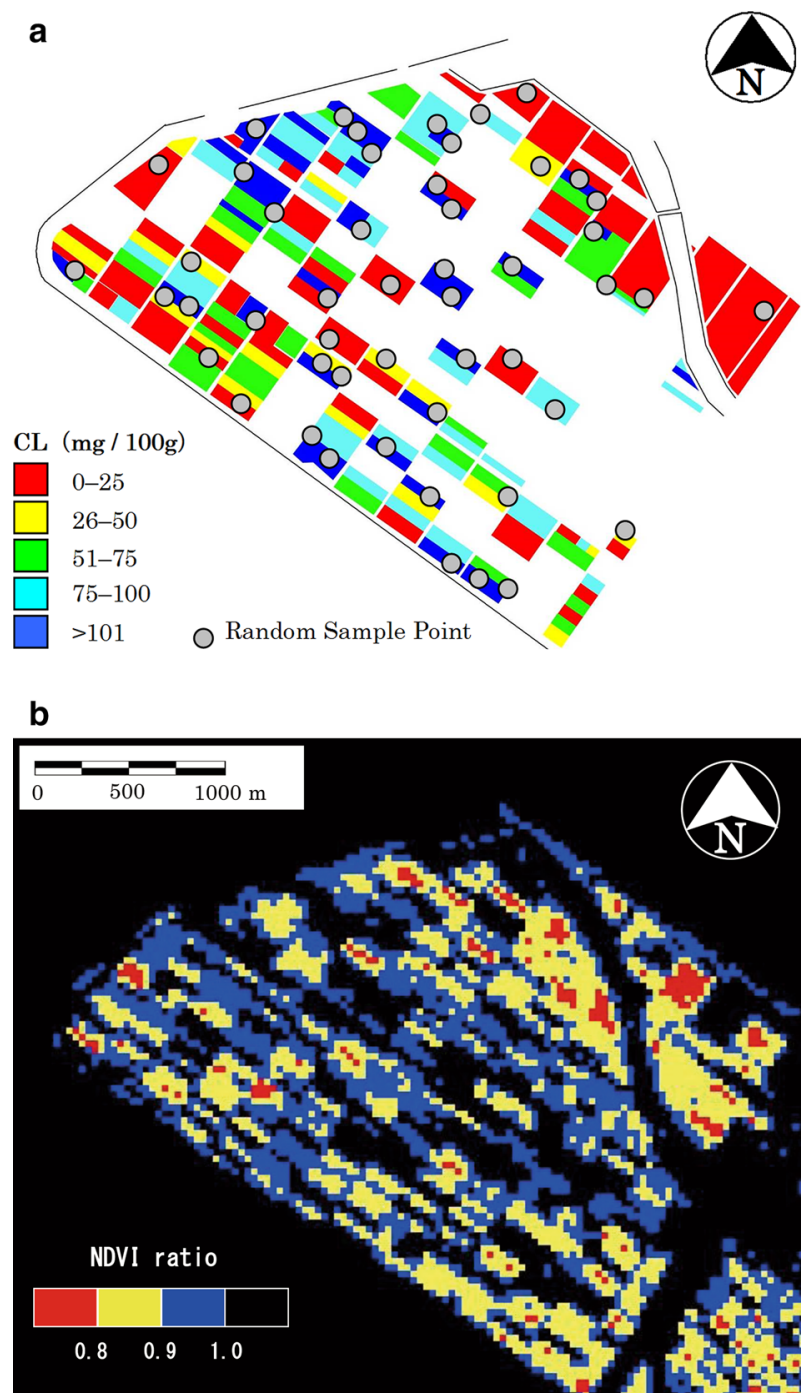

Fig. 5 Comparison of NDVI ratio and soil salinity survey maps. a Soil salinity survey map (constructed from the Kumamoto Prefectural Office data). b NDVI ratio map 1 month after initial damage

NDVI remained comparatively high in former Kagami Town, it was markedly reduced in sea-covered areas of the reclaimed land in Shiranui. Values were especially low in the north- and south-eastern parts of the reclaimed land. Figure 7c) shows the NDVI map on 23 October 1999, approximately 1 month after the salt damage. NDVI was low across the entire area, having further reduced during the 16 days following 7 October (Fig. 7b) indicating a sharp drop in agricultural activity.

As revealed in the pre- and post-typhoon NDVI ratio maps (Fig. 8), salt damage was widely distributed. Comparing Fig. 8a with Fig. 7a, b, we find that NDVI has remarkably dropped in the north-east part of the reclaimed Shiranui land and in the south-eastern reclaimed land near the Hikawa estuary. NDVI values were generally low in the coastal 
Fig. 6 Scatter plot of NDVI ratio versus $\mathrm{EC}$

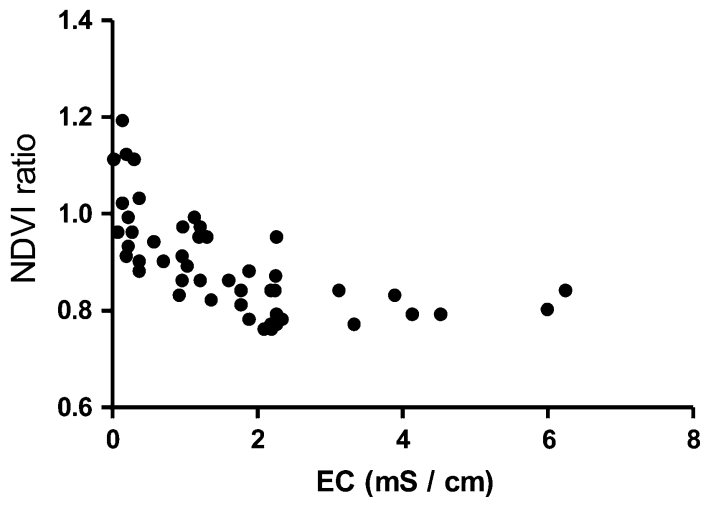

a

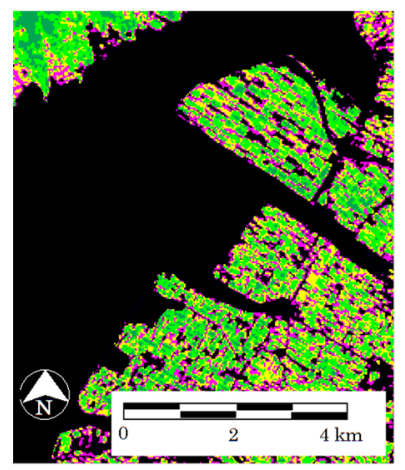

b

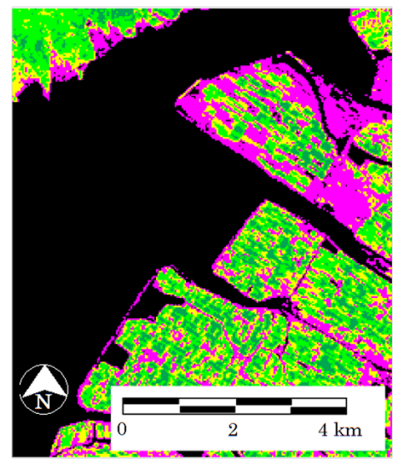

NDVI
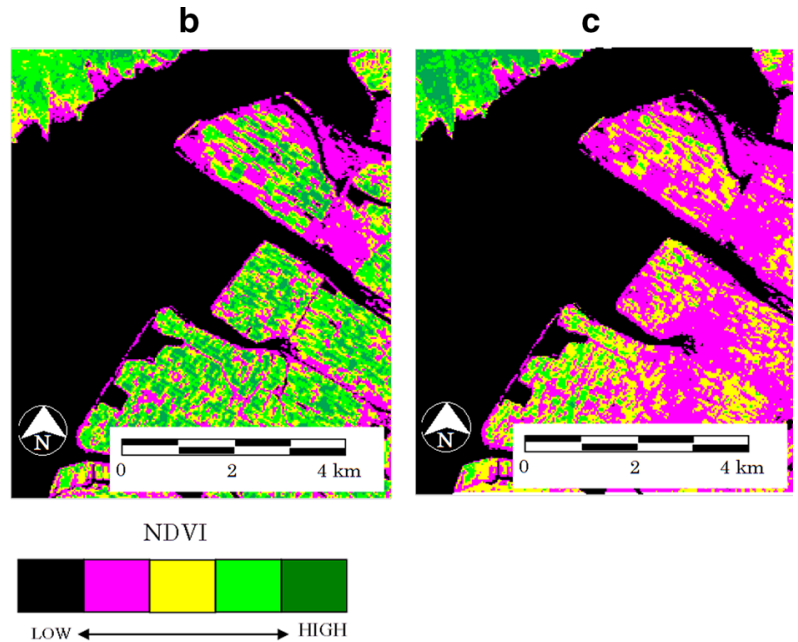

Fig. 7 NDVI maps. a Pre-damage (4/10/1998). b Post-damage (7/10/1999). c Approximately 1 month after the typhoon $(23 / 10 / 1999)$

regions, whereas no change was noticed in the former Kagami Town. Next, comparing Fig. 8b with Fig. 7a, c, we observe low NDVI areas stretching inland of the reclaimed region in Shiranui. The NDVI is reduced even in many regions of Kagami Town, especially in the south-west part of the Kagami River estuary.

Figure 8c shows the NDVI ratio 13 days post-damage and a further 16 days thereafter (approximately 1 month after the damage). Comparing this plot with Fig. 7b, c, we can observe the changes in plant activity induced by salt damage. This comparison offers insight into the salt damage trends across the entire area over a 16-day period following the initial damage.

\section{Discussion}

This section discusses the survey results and analysis of the salt damage following Typhoon 9918. The NDVI ratio maps (Fig. 8a, b) and the damage progression (Fig. 8c) are referred to the flood map of the studied area (Fig. 3a). 
a
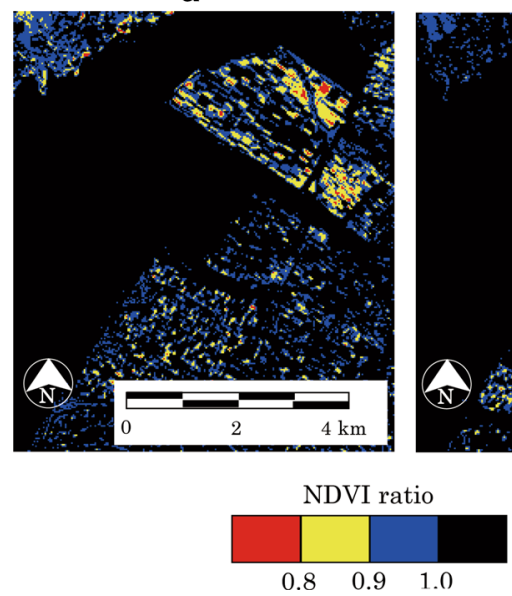

b

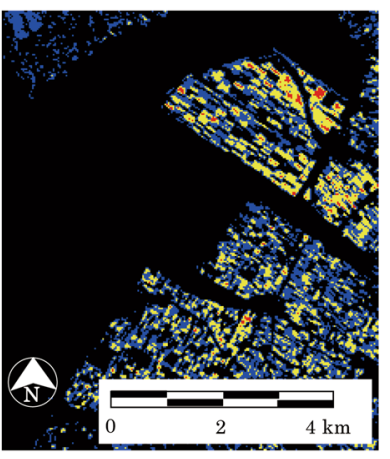

$\mathrm{km}$
C

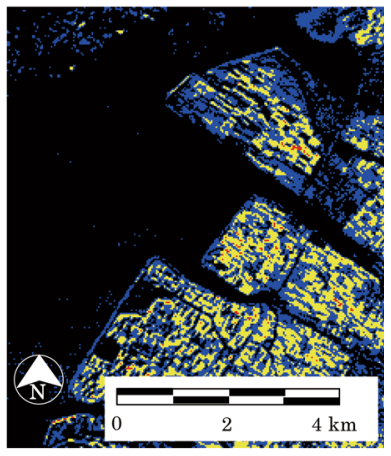

NDVI ratio

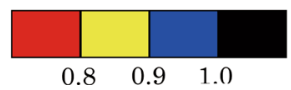

Fig. 8 NDVI ratio maps. a Immediately after the typhoon. b Approximately 1 month after the typhoon. c Damage progression map, approximately 16 days after the typhoon

In Fig. 8a, which maps the damage classification on 7 October 199913 days after the initial salt damage, vegetation activity is primarily reduced in the coastal region of the reclaimed land in Shiranui. The map of the flooded regions (Fig. 3a) shows the flooded area around the reclaimed land stretching to the southeast. Shiranui projects into a narrow bay, giving the appearance of a cover. Consequently, the Shiranui reclaimed land area not only receives an influx of seawater from the south-west during flood tides, but also buffers the waves arriving at the Matsuai ward, Shiranui Town, where 12 lives were lost. These areas are subject to severe flooding and are expected to be densely scattered with high concentrations of sea-salt particles. Therefore, this reclaimed land was damaged more rapidly than other areas.

The reclaimed area, particularly the north- and south-eastern parts, experienced large NDVI reduction. As shown in Fig. 3a, the right bank of the Hachiken River running northeast through the reclaimed land was not flooded, but experienced the same NDVI reduction as the flooded left bank. Salt damage across the entire area implied that even non-flooded areas were scattered with high concentrations of sea-salt particles, which markedly reduced their NDVI.

The NDVI was extremely low in the south-eastern reclaimed land around the Hikawa estuary. Similarly low NDVI values appeared in the north-east. Flooding began on the right bank of the Hikawa River, approximately $3 \mathrm{~km}$ upstream of the river mouth, at 0500 hours on 24 September. The bank started overflowing between 0600 and 0700 hours onto an area approximately $1 \mathrm{~km}$ inland, approximately $50 \mathrm{~m}$ downstream of the Ohashi Bridge. The large volume of seawater inflowing from other inundated areas resulted in large-scale flooding (Takikawa 2000). Hence, the high influx of seawater into this area must have been chiefly responsible for the steep NDVI decline.

In the damage classification map constructed from 27 October 1999 data, approximately 1 month post-damage (Fig. 8b), the damage has spread to the interior of the reclaimed land and former Kagami Town, which appeared relatively unharmed on 7 October. The NDVI dropped in the flooded Hikawa river area of the reclaimed land; subsequently, the damage 
propagated into neighbouring regions. Low NDVI was also observed around the Kagami River estuary. The initial salinity excess continued to internally damage the vegetation, eventually reaching a peak (Gotoh et al. 1999). In these regions, salt brought in from sea air and flooding remains in the soil, where it likely causes gradual damage.

From approximately 0600 hours on 24 September, both banks of the Kagami River flooded over an approximately $3.3 \mathrm{~km}$ length from the river mouth to the centre of former Kagami Town. By around 0700 hours, flooding had ceased apart from a small flooded area of 254 ha. By contrast, 592 ha of land had flooded around the Hikawa River (Takikawa 2000). The Kagami region was flooded with saline seawater over a considerably shorter period than the reclaimed land in the Hikawa estuary region; consequently, damage progression was slower than in the Hikawa estuary region. While the NDVI remained stable for 13 days after the initial damage, a decline was noticed 1 month later. Salt damage had now spread to the inland area of former Kagami Town, not by flooding but probably by salt particles carried in the sea air.

Figure $8 \mathrm{c}$ shows how the damage progresses over time. Sixteen days after the initial salt damage, the NDVI had dropped across the entire study area. Since salt damage affects plant growth functions such as transpiration, reduction in plant activity is frequently a gradual process, characterised by time-dependent progressive damage (Gotoh et al. 1999). This effect appears in our results, indicating that satellite data indirectly reflect the characteristics of progressive salt damage.

Thirteen days post-flooding, initial salt damage is evident in reclaimed land around the Hachiken River and to the south-east (see Fig. 8a), but discontinues thereafter. Crops in this area were probably exposed to high salt concentrations and damaged more rapidly than in other regions. If the crops were already dying by 7 October 1999, no further change in NDVI would be observed.

Hence, on the investigated terrain and flooded areas, the distribution and level of salt damage could be assessed in detail by NDVI monitoring. The salt damage distribution map (Fig. 3b)was produced from surveys conducted by town hall personnel (excluding former Kagami Town, for which no data were available). This map shows the distribution, but not the level, of salt damage. Large-scale on-site surveys are rendered extremely difficult by the cost, labour and time constraints. Furthermore, monitoring of damage trends requires repeated surveying. In contrast, monitoring by remotely sensed satellite data can be easily repeated to identify progressive post-damage vegetation changes, as demonstrated in Fig. 8c.

These observations indicate that salt damage can be assessed from NDVI ratio maps produced from satellite data. That is, satellite data can be exploited for salt damage monitoring.

\section{Conclusion}

In this study, we calculated and analysed the NDVIs from satellite data to monitor soil salt damage caused by Typhoon 9918. The relationship between NDVI and soil salinity is not apparent because salt salinity is rarely investigated over wide areas. However, we acquired detailed data of soil salinity immediately after the typhoon-induced flood, from which we analysed the correlation between NDVI and soil salinity. Although such valuable attempts have been previously made in Japan, we have investigated the most severely damaged area, to our knowledge. Since the typhoon aftermath, a large-scale coastal area in north-east Japan has suffered extensive salt damage by the huge tsunami following the Tohoku 
earthquake in 2011. Our study hints at an evaluation method that efficiently assesses salt damage, which would be invaluable for land recovery following severe natural disasters.

The NDVI ratio is negatively correlated with soil salinity, indicating that salt damage can be effectively monitored by methods based on the NDVI measure. NDVI ratio maps produced from satellite data reveal the characteristic temporal progression of salt damage, before eventually terminating. Thus, satellite data are applicable to salt damage monitoring.

Soft Rush grass is not visually damaged in the first week following initial damage, but thereafter becomes red and withered. This suggests that if salt-damaged Soft Rush can be identified by remote sensing over the area during the first week of exposure, damage to the plant can be minimised.

Acknowledgments We are deeply indebted to the town halls of Ryuhoku Town, Kagami Town, Matsubase Town, Ogawa Town, and Shiranui Town, Kumamoto Prefecture, for providing invaluable data and information.

Open Access This article is distributed under the terms of the Creative Commons Attribution License which permits any use, distribution, and reproduction in any medium, provided the original author(s) and the source are credited.

\section{References}

Aldakheel Y (2011) Assessing NDVI spatial pattern as related to irrigation and soil salinity management in Al-Hassa Oasis. J Indian Soc Remote Sens 39:10

Ashraf M, Harris PJC (2004) Potential biochemical indicators of salinity tolerance in plants. Plant Sci 166:14

Barnes CF, Fritz H, Yoo J (2007) Hurricane disaster assessments with image driven data mining in high resolution satellite imagery. IEEE Trans Geosci Remote Sens 45:10

Chighladze G, Kaleita A, Birrell S (2009) Response of capacitance probes to soil solution nitrate concentration. In: Presentations posters and proceedings of the annual international meeting on agricultural and biosystems engineering (ASABE)

Dan A, Richard H (2002) Sea salt impact on forests in western Norway. Forestry 75:8

Datta K, Jong C (2002) Adverse effect of waterlogging and soil salinity on crop and land productivity in northwest region of Haryana. India Agric Water Manag 57:16

Fritz HM et al (2007) Hurricane Katrina storm surge distribution and field observations on the Mississippi Barrier Islands. Estuar Coast Shelf Sci 74:9

Fritz HM, Kalligeris N, Borrero JC, Broncano P, Orteg E (2008) The 15 August 2007 Peru tsunami runup observations and modeling. Geophys Res Lett 35:5

Fritz HM, Blount CD, Thwin S, Thu MK, Chan N (2009) Cyclone Nargis storm surge in Myanmar. Nat Geosci 2:2. doi:10.1038/ngeo558

Fritz HM et al (2011) Insights on the 2009 South Pacific Tsunami in Samoa and Tonga from field surveys and numerical simulations. Earth Sci Rev 107:10

Ghosh G, Kumar S, Saha S (2012) Hyperspectral satellite data in mapping salt-affected soils using linear spectral unmixing analysis. J Indian Soc Remote Sens 40:8

Gong W, Shen J, Reay W (2007) The hydrodynamic response of the York River estuary to tropical cyclone Isabel, 2003. Estuar Coast Shelf Sci 73:16

Gotoh K, Goto K, Kim E-N (1999) Sugar cane damage caused by typhoon-brought salt water and its countermeasure proposals based on remote sensing techniques. J Jpn Soc Nat Disaster Sci 18:15

Japan Weather Association (2000) Rainy season and typhoon 2000. Japan Weather Association, Japan

Kumamoto Prefecture (2001) Reference material of technological countermeasures against Typhoon 9918

Kume T, Umetsu C, Palanisami K (2009) Impact of the December 2004 tsunami on soil, groundwater and vegetation in the Nagapattinam district. India J Environ Manag 90:8

Kurtulus C, Canbay M, Demir N, Gider G (2009) Salinity investigation of the region east to the Izmit Gulf in Izmit-Kocaeli. J Food Agric Environ 7:4

Larcher W (2003) Physiological Plant Ecology. Springer, Berlin 
Leone A, Menenti M, Sorrentino G (2000) Reflectance spectrometry to study crop response to soil salinity. Ital J Agron 4:11

Liu JW, Shimozono T, Takagawa T, Okayasu A, Fritz MH, Sato S, Tajima Y (2013) The 11 March 2011 Tohoku Tsunami survey in Rikuzentakata and comparison with historical events. Pure Appl Geophys 170:14

McAdoo BG, Richardson N, Borrero J (2007) Inundation distances and runup measurements from ASTER, QuickBird and SRTM data, Aceh Coast. Indones Int J Remote Sens 28:15

Middleton BA (2009) Regeneration of coastal marsh vegetation impacted by hurricanes Katrina and Rita. Wetlands 29:12

Moore A et al (2011) Sedimentary Deposits from the 17 July 2006 Western Java Tsunami, Indonesia: use of grain size analyses to assess tsunami flow depth, speed, and traction carpet characteristics. Pure Appl Geophys 168:11

Nuttall J, Armstrong R (2010) Impact of subsoil physicochemical constraints on crops grown in the Wimmera and Mallee is reduced during dry seasonal conditions. Soil Res 48:15

Overton I, Jolly I, Slavich P, Lewis M, Walker G (2006) Modelling vegetation health from the interaction of saline groundwater and flooding on the Chowilla floodplain. Aust J Bot 54:14

Ramachandran S et al (2005) Ecological impact of tsunami on Nicobar Islands (Camorta, Katchal, Nancowry and Trinkat). Curr Sci 89:6

Rodgers J III, Murrah A, Cooke W (2009) The impact of Hurricane Katrina on the coastal vegetation of the Weeks Bay Reserve Alabama from NDVI data. Estuar Coasts 32:12

Suppasri A, Koshimura S, Imai K, Mas E, Gokon H, Muhari A, Imamura F (2012) Damage characteristic and field survey of the 2011 great east Japan tsunami in Miyagi prefecture. Coast Eng J 54:30

Takikawa K (2000) The high tide disaster by typhoon 9918 in Shiranui Sea. J Soc Civil Eng 85:5

Tchiadje N (2007) Strategies to reduce the impact of salt on crops (rice, cotton and chili) production: a case study of the tsunami-affected area of India. Desalination 206:7

Turhan H (2005) Salinity response of transgenic potato genotypes expressing the oxalate oxidase gene. Turk J Agric For 29:187

Velmurugan A, Swarnam T, Ravisankar N (2006) Assessment of Tsunami impact in South Andaman using remote sensing and GIS. J Indian Soc Remote Sens 34:10

Wang F, Xu Y (2008) Development and application of a remote sensing-based salinity prediction model for a large estuarine lake in the US Gulf of Mexico coast. J Hydrol 360:11

Wilson M, Meyers S, Luther M (2006) Changes in the circulation of Tampa Bay due to Hurricane Frances as recorded by ADCP measurements and reproduced with a numerical ocean model. Estuar Coasts 29:5

Zeng L, Shannon M (2000) Salinity effects on seedling growth and yield components of rice. Crop Sci 40:8 